\title{
Strong convergence theorems of quasi- $\phi$-asymptotically nonexpansive semi-groups in Banach spaces
}

Shih-sen Chang*, Lin Wang, Yong-Kun Tang, Yun-He Zao and Bin Wang

\footnotetext{
* Correspondence: changss@yahoo. $\mathrm{cn}$

College of statistics and mathematics, yunnan university of finance and economics, kunming, yunnan 650221, china
}

\begin{abstract}
The purpose of this article is to modify the Halpern-Mann-type iteration algorithm for quasi- $\phi$ 47H09; 49J25.

Keywords: modified Halpern-Mann-type iteration, quasi- $\phi$-symptotically nonexpansive semi-groups, quasi- $\phi$-nonexpansive semi-groups, weak relatively nonexpansive mapping, relatively nonexpansive semi-groups, generalized projection
\end{abstract}

\section{Introduction}

Throughout this article, we assume that $E$ is a real Banach space with the dual $E^{*}, C$ is a nonempty closed convex subset of $E$ and $J: E \rightarrow 2^{E^{*}}$ is the normalized duality mapping defined by

$$
J(x)=\left\{f^{*} \in E^{*}:\left\langle x, f^{*}\right\rangle=\|x\|^{2}=\left\|f^{*}\right\|^{2}\right\}, x \in E .
$$

Let $T: C \rightarrow E$ be a nonlinear mapping, we denote by $F(T)$ the set of fixed points of $T$.

Recalled that a mapping $T: C \rightarrow C$ is said to be nonexpansive, if

$$
\|T x-T y\| \leq\|x-y\|, \forall x, y \in C .
$$

$T: C \rightarrow C$ is said to be quasi-nonexpansive, if $F(T) \neq \varnothing$ and

$$
\|T x-p\| \leq\|x-p\|, \forall x \in C, p \in F(T) .
$$

$T: C \rightarrow C$ is said to be asymptotically nonexpansive, if there exists a sequence $\left\{k_{n}\right\} \subset$ $[1, \infty)$ with $k_{n} \rightarrow 1$ such that

$$
\left\|T^{n} x-T^{n} y\right\| \leq k_{n}\|x-y\|, \forall x, y \in C, n \geq 1 .
$$

$T: C \rightarrow C$ is said to be quasi-asymptotically nonexpansive, if $F(T) \neq \varnothing$ and there exists a sequence $\left\{k_{n}\right\} \subset[1, \infty]$ with $k_{n} \rightarrow 1$ such that

$$
\left\|T^{n} x-p\right\| \leq k_{n}\|x-p\|, \forall x \in C, p \in F(T), n \geq 1 .
$$

One parameter family $\mathscr{T}:=\{T(t): t \geq 0\}$ of mappings from $C$ into $C$ is said to be nonexpansive semi-group, if the following conditions are satisfied:

(i) $T(0) x=x$ for all $x \in C$;

\section{空


(ii) $T(s+t)=T(s) T(t) \forall s, t \geq 0$;

(iii) for each $x \in C$, the mapping $t \mapsto T(t) x$ is continuous;

(iv) ||$T(t) x-T(t) y\|\leq\| x-y \|, \forall x, y \in C$.

We use $F(\mathscr{J})$ to denote the common fixed point set of the nonexpansive semigroup $\mathscr{J}$, i.e., $F(\mathscr{J}):=\bigcap_{t \geq 0} F(T(t))$.

One parameter family $\mathscr{T}:=\{T(t): t \geq 0\}$ of mappings from $C$ into $C$ is said to be quasi-nonexpansive semi-group, if $F(\mathscr{J}) \neq \emptyset$, and the above conditions (i)-(iii) and the following condition (v) are satisfied:

(v) $\|T(t) x-p\| \leq\|x-p\|, \forall x \in C, p \in F(\mathscr{J}), t \geq 0$.

One parameter family $\mathscr{T}:=\{T(t): t \geq 0\}$ of mappings from $C$ into $C$ is said to be asymptotically nonexpansive semi-group, if there exists a sequence $\left\{k_{n}\right\} \subset[1, \infty)$ with $k_{n} \rightarrow 1$ such that the above conditions (i)-(iii) and the following condition (vi) are satisfied:

(vi) $\left\|T^{n}(t) x-T^{n}(t) y\right\| \leq k_{n}\|x-y\|, \forall x, y \in C, n \geq 1, t \geq 0$.

One parameter family $\mathscr{T}:=\{T(t): t \geq 0\}$ of mappings from $C$ into $C$ is said to be quasi asymptotically nonexpansive semi-group, if $F(\mathscr{J}) \neq \emptyset$, and there exists a sequence $\left\{k_{n}\right\} \subset[1, \infty)$ with $k_{n} \rightarrow 1$ such that the above conditions (i)-(iii) and the following condition (vii) are satisfied:

(vii) $\left\|T^{n}(t) x-p\right\| \leq k_{n}\|x-p\|, \forall x \in C, p \in F(\mathscr{J}), t \geq 0, n \geq 1$.

As well known, the construction of fixed points of nonexpansive mappings (asymptotically nonexpansive mappings), and of common fixed points of nonexpansive semigroups (asymptotically nonexpansive semi-groups) is an important problem in the theory of nonexpansive mappings and its applications, in particular, in image recovery, convex feasibility problem, and signal processing problem (see, for example [1-4]).

Iterative approximation of fixed point for nonexpansive mappings, asymptotically nonexpansive mappings, nonexpansive semi-groups, and asymptotically nonexpansive semi-groups in Hilbert or Banach spaces has been studied extensively by many authors (see, for example, [5-30] and the references therein).

The purpose of this article is to introduce the concept of quasi- $\phi$-asymptotically nonexpansive semi-groups and to modify the Halpern and Mann-type iteration algorithm $[14,15]$ for quasi- $\phi$-asymptotically nonexpansive semi-groups and to have the strong convergence under a limit condition only in the framework of Banach spaces. The results presented in the article improve and extend the corresponding results of Suzuki [5], Xu [6], Chang et al. [7], Zhang [8], Chang et al. [9], Cho et al. [11], Thong [12], Buong [13], Mann [14], Halpern [15], Qin et al. [16], Nakajo and Takahashi [19], Kang et al. [23], Chang et al. [24], and others.

\section{Preliminaries}

In the sequel, we assume that $E$ is a smooth, strictly convex and reflexive Banach space and $C$ is a nonempty closed convex subset of $E$. In what follows, we always use $\phi$ : $E \times E \rightarrow \mathscr{R}^{+}$to denote the Lyapunov functional defined by

$$
\phi(x, y)=\|x\|^{2}+2\langle x, J y\rangle+\|y\|^{2}, \forall x, y \in E .
$$

It is obvious from the definition of $\phi$ that

$$
(\|x\|-\|y\|)^{2} \leq \phi(x, y) \leq(\|x\|+\|y\|)^{2}, \forall x, y \in E .
$$


and

$$
\phi\left(x, J^{-1}(\lambda J y+(1-\lambda) J z) \leq \lambda \phi(x, y)+(1-\lambda) \phi(x, z), \forall x, y \in E .\right.
$$

Following Alber [31], the generalized projection $\Pi_{C}: E \rightarrow C$ is defined by

$$
\Pi_{C}(x)=\arg \inf _{y \in C} \phi(y, x), \forall x \in E .
$$

Lemma 2.1 [31]. Let $E$ be a smooth, strictly convex, and reflexive Banach space and $C$ be a nonempty closed convex subset of $E$. Then the following conclusions hold:

(a) $\phi\left(x, \Pi_{C} y\right)+\phi\left(\Pi_{C} y, y\right) \leq \phi(x, y)$ for all $x \in C$ and $y \in E$;

(b) If $x \in E$ and $z \in C$, then $z=\Pi_{C} x \Leftrightarrow\langle z-y, J x-J z\rangle \geq 0, \forall y \in C$;

(c) For $x, y \in E, \phi(x, y)=0$ if and only if $x=y$;

Remark 2.2. If $E$ is a real Hilbert space $H$, then $\phi(x, y)=\|x-y\|^{2}$ and $\Pi_{C}=P_{C}$ (the metric projection of $H$ onto $C$ ).

Definition 2.3. A mapping $T: C \rightarrow C$ is said to be closed if, for any sequence $\left\{x_{n}\right\} \subset$ $C$ with $x_{n} \rightarrow x$ and $T x_{n} \rightarrow y$, then $T x=y$.

Definition 2.4. (1) A mapping $T: C \rightarrow C$ is said to be quasi-ф-nonexpansive, if $F(T)$ $\neq \varnothing$ and

$$
\phi(p, T x) \leq \phi(p, x), \forall x \in C, p \in F(T)
$$

(2) A mapping $T: C \rightarrow C$ is said to be quasi- $\phi$-asymptotically nonexpansive, if $F(T) \neq$ $\varnothing$ and there exists a real sequence $\left\{k_{n}\right\} \subset[1, \infty), k_{n} \rightarrow 1$ such that

$$
\phi\left(p, T^{n} x\right) \leq k_{n} \phi(p, x), \forall n \geq 1, x \in C, p \in F(T) .
$$

Remark 2.5 [23]. (1) From the definitions, it is obvious that a quasi- $\phi$-nonexpansive mapping is a quasi- $\phi$-asymptotically nonexpansive mapping. However, the converse is not true.

(2) Especially, if $E$ is a real Hilbert space, than a quasi- $\phi$-nonexpansive mapping is a quasi-nonexpansive mapping and a quasi- $\phi$-asymptotically nonexpansive mapping is a quasi-asymptotically nonexpansive mapping.

Example 2.6 [24]. Let $E$ be a uniformly smooth and strictly convex Banach space and $A: E \rightarrow E^{*}$ be a maximal monotone mapping such that $A^{-1} 0 \neq \varnothing$, then $J_{r}=(J+$ $r A)^{-1} J$ is closed and quasi- $\phi$-nonexpansive from $E$ onto $D(A)$;

Example 2.7 [23]. Let $\Pi_{C}$ be the generalized projection from a smooth, reflexive, and strictly convex Banach space $E$ onto a nonempty closed convex subset $C$ of $E$, then $\Pi_{C}$ is a closed and quasi- $\phi$-nonexpansive from $E$ onto $C$.

Lemma 2.8 Let $E$ be a uniformly convex and smooth Banach space and let $\left\{x_{n}\right\}$ and $\left\{y_{n}\right\}$ be two sequences of $E$. If $\phi\left(x_{n}, y_{n}\right) \rightarrow 0$ and either $\left\{x_{n}\right\}$ or $\left\{y_{n}\right\}$ is bounded, then $\|$ $x_{n}-y_{n} \| \rightarrow 0$.

Lemma 2.9 [23]. Let $E$ be a real uniformly smooth and strictly convex Banach space with Kadec-Klee property and $C$ be a nonempty closed and convex subset of $E$. Let $T$ : $C \rightarrow C$ be a closed and quasi- $\phi$-asymptotically nonexpansive mapping, then $F(T)$ is a closed convex subset of $C$.

Definition 2.10. (I) Let $E$ be a real Banach space, $C$ be a nonempty closed convex subset of $E . \mathscr{T}:=\{T(t): t \geq 0\}$ be one parameter family of mappings from $C$ into $C . \mathscr{J}$ is said to be 
(1) quasi-ф-nonexpansive semi-group, if $\mathscr{F}=\bigcap_{t \geq 0} F(T(t)) \neq \emptyset$ and the following conditions are satisfied

(i) $T(0) x=x$ for all $x \in C$;

(ii) $T(s+t)=T(s) T(t) \forall s, t \geq 0$;

(iii) for each $x \in C$, the mapping $t \mapsto T(t) x$ is continuous;

(iv) $\phi(p, T(t) x) \leq \phi(p, x), \forall t \geq 0, p \in \mathscr{F} x \in C$.

(2) $\mathscr{J}$ is said to be quasi- $\phi$-asymptotically nonexpansive semi-group, if the set $\mathscr{F}=\bigcap_{t \geq 0} F(T(t))$ is nonempty, and there exists a sequence $\left\{k_{n}\right\} \subset[1, \infty)$, with $k_{n} \rightarrow 1$ such that the conditions (i)-(iii) and the following conditions (v) are satisfied:

(v) $\phi\left(p, T^{n}(t) x\right) \leq k_{n} \phi(p, x), \forall t \geq 0, p \in \mathscr{F}, n \geq 1, x \in C$.

(II) A quasi- $\phi$-asymptotically nonexpansive semi-group $\mathscr{J}$ is said to be uniformly Lipschitzian, if there exists a bounded measurable function $L:[0, \infty) \rightarrow(0, \infty)$ such that

$$
\left\|T^{n}(t) x-T^{n}(t) y\right\| \leq L(t)\|x-y\|, \forall x, y \in C, \forall n \geq 1, t \geq 0 .
$$

\section{Main results}

Theorem 3.1. Let $C$ be a nonempty closed convex subset of a real uniformly convex and uniformly smooth Banach space $E$. Let $\mathscr{T}:=\{T(t): t \geq 0\}$ be a closed, uniformly $L$-Lipschitz and quasi- $\phi$-asymptotically nonexpansive semi-group with sequence $\left\{k_{n}\right\} \subset$ $[1, \infty), k_{n} \rightarrow 1$. Let $\left\{\mapsto_{n}\right\}$ be a sequence in $[0,1]$ and $\left\{\beta_{n}\right\}$ be a sequence in $(0,1)$ satisfying the following conditions:

(i) $\lim _{n \rightarrow \infty} \alpha_{n}=0$;

(ii) $0<\lim _{\operatorname{linf}}{ }_{n \rightarrow \infty} \beta_{n} \leq \lim \sup _{n \rightarrow \infty} \beta_{n}<1$.

Let $\left\{x_{n}\right\}$ be a sequence generated by

$$
\left\{\begin{array}{l}
x_{1} \in \text { E chosen arbitrarily; } C_{1}=C_{,} \\
y_{n, t}=J^{-1}\left[\alpha_{n} J x_{1}+\left(1-\alpha_{n}\right)\left(\beta_{n} J x_{n}+\left(1-\beta_{n}\right) J T^{n}(t) x_{n}\right)\right], t \geq 0, \\
C_{n+1}=\left\{z \in C_{n}: \sup _{t \geq 0} \phi\left(z, y_{n, t}\right) \leq \alpha_{n} \phi\left(z, x_{1}\right)+\left(1-\alpha_{n}\right) \phi\left(z, x_{n}\right)+\xi_{n}\right\} \\
x_{n+1}=\Pi_{C_{n+1}} x_{1}, \forall n \geq 1,
\end{array}\right.
$$

where $\mathscr{F}:=\bigcap_{t \geq 0}^{\infty} F(T(t)), \xi_{n}=\left(k_{n}-1\right) \sup _{p \in \mathscr{F}} \phi\left(p, x_{n}\right), \Pi_{C_{n+1}}$ is the generalized projection of $E$ onto $C_{n+1}$. If $\mathscr{F}$ is bounded in $C$, then $\left\{x_{n}\right\}$ converges strongly to $\Pi_{\mathscr{F}} x_{1}$.

Proof. (I) First we prove that $\mathscr{F}$ and $C_{n}, n \geq 1$ all are closed and convex subsets in $C$. In fact, it follows from Lemma 2.9 that $F(T(t)), t \geq 0$ is a closed and convex subset of $C$. Therefore, $\mathscr{F}$ is closed and convex in $C$.

Again by the assumption that $C_{1}=C$ is closed and convex. Suppose that $C_{n}$ is closed and convex for some $n \geq 2$. In view of the definition of $\phi$ we have that

$$
\begin{aligned}
C_{n+1} & =\left\{z \in C_{n}: \sup _{t \geq 0} \phi\left(z, y_{n, t}\right) \leq \alpha_{n} \phi\left(z, x_{1}\right)+\left(1-\alpha_{n}\right) \phi\left(z, x_{n}\right)+\xi_{n}\right\} \\
& =\bigcap_{t \geq 0}\left\{z \in C: \phi\left(z, y_{n, t}\right) \leq \alpha_{n} \phi\left(z, x_{1}\right)+\left(1-\alpha_{n}\right) \phi\left(z, x_{n}\right)+\xi_{n}\right\} \bigcap C_{n} \\
& =\bigcap_{t \geq 0}\left\{z \in C: 2 \alpha_{n}\left\langle z, J x_{1}\right\rangle+2\left(1-\alpha_{n}\right)\left\langle z, J x_{n}\right\rangle-2\left\langle z, J y_{n, t}\right\rangle\right. \\
& \left.\leq \alpha_{n}\left\|x_{1}\right\|^{2}+\left(1-\alpha_{n}\right)\left\|x_{n}\right\|^{2}-\left\|y_{n,}\right\|^{2}\right\} \bigcap C_{n} .
\end{aligned}
$$

This shows that $C_{n+1}$ is closed and convex. The conclusion is proved.

(II) Now we prove that $\mathscr{F} \subset C_{n,}, \forall n \geq 1$. 
In fact, it is obvious that $\mathscr{F} \subset C_{1}=C$. Suppose that $\mathscr{F} \subset C_{n}$, for some $n \geq 2$. Letting

$$
w_{n, t}=J^{-1}\left(\beta_{n} J x_{n}+\left(1-\beta_{n}\right) J T^{n}(t) x_{n}\right), t \geq 0,
$$

it follows from (2.3) that for any $u \in \mathscr{F} \subset C_{n, \text {, we have }}$

$$
\begin{aligned}
\phi\left(u, y_{n, t}\right) & =\phi\left(u, J^{-1}\left(\alpha_{n} J x_{1}+\left(1-\alpha_{n}\right) J w_{n, t}\right)\right) \\
& \leq \alpha_{n} \phi\left(u, x_{1}\right)+\left(1-\alpha_{n}\right) \phi\left(u, w_{n, t}\right),
\end{aligned}
$$

and

$$
\begin{aligned}
\phi\left(u, w_{n, t}\right) & =\phi\left(u, J^{-1}\left(\beta_{n} J x_{n}+\left(1-\beta_{n}\right) J T^{n}(t) x_{n}\right)\right. \\
& \leq \beta_{n} \phi\left(u, x_{n}\right)+\left(1-\beta_{n}\right) \phi\left(u, T^{n}(t) x_{n}\right) \\
& \leq \beta_{n} \phi\left(u, x_{n}\right)+\left(1-\beta_{n}\right) k_{n} \phi\left(u, x_{n}\right) \\
& =\phi\left(u, x_{n}\right)+\left(1-\beta_{n}\right)\left(k_{n}-1\right) \phi\left(u, x_{n}\right) .
\end{aligned}
$$

Therefore, we have

$$
\begin{aligned}
\sup _{t \geq 0} \phi\left(u, y_{n, t}\right) & \leq \alpha_{n} \phi\left(u, x_{1}\right)+\left(1-\alpha_{n}\right)\left\{\phi\left(u, x_{n}\right)+\left(1-\beta_{n}\right)\left(k_{n}-1\right) \phi\left(u, x_{n}\right)\right\} \\
& \leq \alpha_{n} \phi\left(u, x_{1}\right)+\left(1-\alpha_{n}\right) \phi\left(u, x_{n}\right)+\left(k_{n}-1\right) \sup _{p \in \mathscr{F}} \phi\left(p, x_{n}\right) \\
& =\alpha_{n} \phi\left(u, x_{1}\right)+\left(1-\alpha_{n}\right) \phi\left(u, x_{n}\right)+\xi_{n},
\end{aligned}
$$

where $\xi_{n}=\left(k_{n}-1\right) \sup _{p \in \mathscr{F}} \phi\left(p, x_{n}\right)$. This shows that $u \in C_{n+1}$, and so $\mathscr{F} \subset C_{n+1}$. The conclusion is proved.

(III) Next we prove that $\left\{x_{n}\right\}$ is a Cauchy sequence in $C$.

In fact, since $x_{n}=\prod_{C_{n}} x_{1}$, from Lemma 2.1(b) we have

$$
\left\langle x_{n}-y, J x_{1}-J x_{n}\right\rangle \geq 0, \forall y \in C_{n} .
$$

Again since $\mathscr{F} \subset C_{n} \forall n \geq 1$, we have

$$
\left\langle x_{n}-u, J x_{1}-J x_{n}\right\rangle \geq 0, \forall u \in \mathscr{F} .
$$

It follows from Lemma 2.1(a) that for each $u \in \mathscr{F}$ and for each $n \geq 1$

$$
\phi\left(x_{n}, x_{1}\right)=\phi\left(\Pi_{C_{n}} x_{1}, x_{1}\right) \leq \phi\left(u, x_{1}\right)-\phi\left(u, x_{n}\right) \leq \phi\left(u, x_{1}\right) .
$$

Therefore $\left\{\phi\left(x_{n}, x_{1}\right)\right\}$ is bounded. By virtue of (2.2), $\left\{x_{n}\right\}$ is also bounded. Since $x_{n}=\prod_{C_{n}} x_{1}$ and $x_{n+1}=\prod_{C_{n}} x_{1} \in C_{n+1} \subset C_{n}$, we have $\phi\left(x_{n}, x_{1}\right) \leq \phi\left(x_{n+1}, x_{1}\right), \forall n \geq 1$. This implies that $\left\{\phi\left(x_{n}, x_{1}\right)\right\}$ is nondecreasing. Hence, the $\operatorname{limit}_{\lim _{n \rightarrow \infty}} \phi\left(x_{n}, x_{1}\right)$ exists. By the construction of $\left\{C_{n}\right\}$, for any positive integer $m \geq n$, we have $C_{m} \subset C_{n}$ and $x_{m}=$ $\Pi_{C m} x_{1} \in C_{n}$. This show that

$$
\phi\left(x_{m}, x_{n}\right)=\phi\left(x_{m}, \Pi_{C_{n}} x_{1}\right), \leq \phi\left(x_{m}, x_{1}\right)-\phi\left(x_{n}, x_{1}\right) \rightarrow 0 \text { as } n, m \rightarrow \infty .
$$

It follows from Lemma 2.8 that $\lim _{n, m \rightarrow \infty}\left\|x_{m}-x_{n}\right\|=0$. Hence $\left\{x_{n}\right\}$ is a Cauchy sequence in $C$. Since $C$ is complete, without loss of generality, we can assume that $x_{n}$ $\rightarrow p^{*}$ (some point in $C$ ).

By the assumption, it is easy to see that

$$
\lim _{n \rightarrow \infty} \xi_{n}=\lim _{n \rightarrow \infty}\left(k_{n}-1\right) \sup _{p \in \mathscr{F}} \phi\left(p, x_{n}\right)=0 .
$$

(IV) Now we prove that $p^{*} \in \mathscr{F}$. 
In fact, since $x_{n+1} \in C_{n+1}$ and $\alpha_{n} \rightarrow 0$, follows from (3.1) and (3.5) that

$$
\sup _{t \geq 0} \phi\left(x_{n+1}, y_{n, t}\right) \leq \alpha_{n} \phi\left(x_{n+1}, x_{1}\right)+\left(1-\alpha_{n}\right) \phi\left(x_{n+1}, x_{n}\right)+\xi_{n} \rightarrow 0(\text { as } n \rightarrow \infty) \text {. }
$$

Since $x_{n} \rightarrow p^{*}$, by virtue of Lemma 2.8 for each $t \geq 0$

$$
\lim _{n \rightarrow \infty} y_{n, t}=p^{*} \text {. }
$$

Since $\left\{x_{n}\right\}$ is bounded, and $\mathscr{T}:=\{T(t): t \geq 0\}$ is a quasi- $\phi$-asymptotically nonexpansive semi-group with sequence $\left\{k_{n}\right\} \subset[1, \infty), k_{n} \rightarrow 1$, for any given $p \in \mathscr{F}$, we have

$$
\phi\left(p, T^{n}(t) x_{n}\right) \leq k_{n} \phi\left(p, x_{n}\right), \forall t \geq 0 .
$$

This implies that $\left\{T^{n}(t) x_{n}\right\}_{t \geq 0}$ is uniformly bounded. Since for each $t \geq 0$,

$$
\begin{aligned}
\left\|w_{n, t}\right\| & =\left\|J^{-1}\left(\beta_{n} J x_{n}+\left(1-\beta_{n}\right) J T^{n}(t) x_{n}\right)\right\| \\
& \leq \beta_{n}\left\|x_{n}\right\|+\left(1-\beta_{n}\right)\left\|T^{n}(t) x_{n}\right\| \\
& \leq \max \left\{\left\|x_{n}\right\|,\left\|T^{n}(t) x_{n}\right\|\right\} .
\end{aligned}
$$

This implies that $\left\{w_{n, t}\right\}_{t \geq 0}$ is also uniformly bounded.

Since $\alpha_{n} \rightarrow 0$, from (3.1) we have

$$
\lim _{n \rightarrow \infty}\left\|J y_{n, t}-J w_{n, t}\right\|=\lim _{n \rightarrow \infty} \alpha_{n}\left\|J x_{1}-J w_{n, t}\right\|=0, \text { for } t \geq 0 .
$$

Since $E^{*}$ is uniformly smooth, $J^{-1}$ is uniformly continuous on each bounded subset of $E^{*}$, it follows from (3.6) and (3.7) that

$$
\lim _{n \rightarrow \infty} w_{n, t}=p^{*} \text { for each } t \geq 0 \text {. }
$$

Since $x_{n} \rightarrow p^{*}$ and $J$ is uniformly continuous on each bounded subset of $E$, we have $J$ $x_{n} \rightarrow J p^{*}$, and so for each $t \geq 0$

$$
\begin{aligned}
0 & =\lim _{n \rightarrow \infty}\left\|J w_{n, t}-J p^{*}\right\|=\lim _{n \rightarrow \infty}\left\|\beta_{n} J x_{n}+\left(1-\beta_{n}\right) J T^{n}(t) x_{n}-J p^{*}\right\| \\
& =\lim _{n \rightarrow \infty}\left\|\beta_{n}\left(J x_{n}-J p^{*}\right)+\left(1-\beta_{n}\right)\left(J T^{n}(t) x_{n}-J p^{*}\right)\right\| \\
& =\lim _{n \rightarrow \infty}\left(1-\beta_{n}\right)\left\|J T^{n}(t) x_{n}-J p^{*}\right\| .
\end{aligned}
$$

By condition (ii), we have that

$$
\lim _{n \rightarrow \infty}\left\|\left(J T^{n}(t) x_{n}-J p^{*}\right)\right\|=0 \text { uniformly in } t \geq 0 .
$$

Since $J$ is uniformly continuous, this shows that $\lim _{n \rightarrow \infty} \mathrm{T}^{n}(t) x_{n}=p^{*}$ uniformly in $t \geq 0$.

Again by the assumptions that the semi-group $\mathscr{T}:=\{T(t): t \geq 0\}$ is closed and uniformly $L$-Lipschitzian, thus we have

$$
\begin{aligned}
\| T^{n+1}(t) x_{n}-T^{n+1}(t) x_{n} \leq & \left\|T^{n+1}(t) x_{n}-T^{n+1}(t) x_{n+1}\right\|+\left\|T^{n+1}(t) x_{n+1}-x_{n+1}\right\| \\
& +\left\|x_{n+1}-x_{n}\right\|+\left\|x_{n}-T^{n}(t) x_{n}\right\| \\
\leq & (L(t)+1)\left\|x_{n+1}-x_{n}\right\|+\left\|T^{n+1}(t) x_{n+1}-x_{n+1}\right\|+\left\|x_{n}-T^{n}(t) x_{n}\right\| .
\end{aligned}
$$

Since $\lim _{n \rightarrow \infty} \mathrm{T}^{n}(t) x_{n}=p^{*}$ uniformly in $t \geq 0, x_{n} \rightarrow p^{*}$ and $L(t):[0, \infty) \rightarrow[0, \infty)$ is a bounded and measurable function, these together with (3.9) imply that

$$
\lim _{n \rightarrow \infty}\left\|T^{n+1}(t) x_{n}-T^{n}(t) x_{n}\right\|=0, \text { uniformly in } t \geq 0,
$$


and so

$$
\lim _{n \rightarrow \infty} T^{n+1}(t) x_{n}=p^{*}, \text { uniformly in } t \geq 0,
$$

i.e.,

$\lim _{n \rightarrow \infty} T(t) T^{n}(t) x_{n}=p^{*}$, uniformly in $t \geq 0$.

In view of the closeness of the semi-group $\mathscr{J}$, it yields that $T(t) p^{*}=p^{*}$, i.e., $p^{*} \in F(T$ $(t))$. By the arbitrariness of $t \geq 0$, we have $p^{*} \in \mathscr{F}:=\bigcap_{t \geq 0} F(T(t))$.

(V) Finally, we prove that $x_{n} \rightarrow p^{*}=\Pi_{\mathscr{F}} x_{1}$.

\section{SHIH-SEN CHANG*}

Let $w=\Pi_{\mathscr{F}} x_{1}$. Since $w \in \mathscr{F} \subset C_{n}$ and $x_{n}=\prod_{C_{n}} x_{1}$, we have $\phi\left(x_{n}, x_{1}\right) \leq \phi\left(w, x_{1}\right), \forall n$ $\geq$

1. This implies that

$$
\phi\left(p^{*}, x_{1}\right)=\lim _{n \rightarrow \infty} \phi\left(x_{n}, x_{1}\right) \leq \phi\left(w, x_{1}\right) .
$$

In view of the definition of $\Pi_{\mathscr{F}} x_{1}$, from (3.10) we have $p^{*}=w$. Therefore, $x_{n} \rightarrow p^{*}=\Pi_{\mathscr{F}} x_{1}$. This completes the proof of Theorem 3.1.

Theorem 3.2. Let $E, C,\left\{\alpha_{n}\right\},\left\{\beta_{n}\right\}$ be the same as in Theorem 3.1. Let $\mathscr{T}:=\{T(t): t \geq 0\}$ be a closed, quasi- $\phi$ - nonexpansive semi-group such that the set $\mathscr{F}:=\bigcap_{t \geq 0} F(T(t))$ is nonempty. Let $\left\{x_{n}\right\}$ be the sequence generated by

$$
\left\{\begin{array}{l}
x_{1} \in E \text { chosen arbitrarily; } C_{1}=C, \\
y_{n, t}=J^{-1}\left[\alpha_{n} J x_{1}+\left(1-\alpha_{n}\right)\left(\beta_{n} J x_{n}+\left(1-\beta_{n}\right) J T(t) x_{n}\right)\right], t \geq 0, \\
C_{n+1}=\left\{z \in C_{n}: \sup _{t \geq 0} \phi\left(z, y_{n, t}\right) \leq \alpha_{n} \phi\left(z, x_{1}\right)+\left(1-\alpha_{n}\right) \phi\left(z, x_{n}\right)\right\} \\
x_{n+1}=\Pi_{C_{n+1}} x_{1}, \forall n \geq 1 .
\end{array}\right.
$$

Then the sequence $\left\{x_{n}\right\}$ converges strongly to $\Pi_{\mathscr{F}} x_{1}$,

Proof. Since $\mathscr{T}:=\{T(t): t \geq 0\}$ is a closed, quasi- $\phi$-nonexpansive semi-groups, by Remark 2.5, it is a closed, uniformly Lipschitzian and quasi- $\phi$ - asymptotically nonexpansive semi-group with sequence $\left\{k_{n}=1\right\}$. Hence $\xi_{n}=\left(k_{n}-1\right) \sup _{u \in \mathscr{F}} \phi\left(u, x_{n}\right)=0$. Therefore the conditions appearing in Theorem 3.1: " $\mathscr{F}$ is a bounded subset in $C$ " and “T := $\{T(t): t \geq 0\}$ is uniformly Lipschitzian" are no use here. Therefore all conditions in Theorem 3.1 are satisfied. The conclusion of Theorem 3.2 can be obtained from Theorem 3.1 immediately.

Remark 3.3. Theorems 3.1 and 3.2 improve and extend the corresponding results of Suzuki [5], Xu [6], Chang et al. Chang et al. [7], Zhang [8], Chang et al. [9], Cho et al. [11], Thong [12], Buong [13], Mann [14], Halpern [15], Qin et al. [16], Nakajo and Takahashi [19], Kang et al. [23], Chang et al. [24], and others.

Acknowledgements

The authors would like to express their thanks to the referees for their helpful suggestions and comments. This study was supported by the Natural Science Foundation of Yunnan Province, Grant No.2011FB074. 


\section{Competing interests}

The authors declare that they have no competing interests.

Received: 19 November 2011 Accepted: 15 February 2012 Published: 15 February 2012

\section{References}

1. Byrne, C: A unified treatment of some iterative algorithms in signal processing and image construction. Inverse Probl. 20, 103-120 (2004). doi:10.1088/0266-5611/20/1/006

2. Combettes, PL: The convex feasibility problem in inage recovery. In: Hawkes P (ed.) Advances in Imaging and Electron Physics, vol. 95, pp. 155-270. Academic Press, New York (1996)

3. Kitahara, S, Takahashi, W: Image recovery by convex combinations of sunny nonexpansive retractions. Topol Methods Nonlinear Anal. 2, 333-342 (1993)

4. Plubtieng, S, Ungchittrakool, K: Hybrid iterative methods for convex feasibility problems and fixed point problems of relatively nonexpansive mappings in Banach spaces. Fixed Point Theory and Applications 2008, 19 (2008). Article ID 583082, doi:10.1155/2008/583082

5. Suzuki, T: On strong convergence to common fixed points of nonexpansive semigroups in Hilbert spaces. Proc Am Math Soc. 131, 2133-2136 (2003). doi:10.1090/S0002-9939-02-06844-2

6. $\mathrm{Xu}, \mathrm{HK}$ : A strong convergence theorem for contraction semigruops in Banach spaces. Bull Aust Math Soc. 72, 371-379 (2005). doi:10.1017/S000497270003519X

7. Chang, SS, Yang, L, Liu, JA: Strong convergence theorem for nonexpansive semi-groups in Banach spaces. Appl Math Mech. 28, 1287-1297 (2007). doi:10.1007/s10483-007-1002-x

8. Zhang, S-s: Convergence theorem of common fixed points for Lipschitzian pseudo-contraction semi-groups in Banach spaces. Appl Math Mech., English 30(2), 145-C152 (2009). doi:10.1007/s10483-009-0202-y

9. Chang, SS, Joseph Lee, HW, Chan, CK: Convergence theorem of common fixed point for aysmptotically nonexpansive semigroups in Banach spaces. Appl Math Comput. 212, 60-65 (2009). doi:10.1016/j.amc.2009.01.086

10. Cho, SY, Kang, SM: Approximation of fixed points of pseudocontraction semigroups based on a viscosity iterative process. Appl Math Lett. 24, 224-228 (2011). doi:10.1016/j.aml.2010.09.008

11. Cho, YJ, Ciric, L, Wang, S-h: Convergence theorems for nonexpansive semigroups in CAT(0) spaces. Nonlinear Anal (2011). doi:10.1016/j.na.2011.05.082

12. Thong, DV: An implicit iteration process for nonexpansive semigroups. Nonlinear Anal (2011). doi:10.1016/j. na.2011.05.090

13. Buong, N: Hybrid Ishikawa iterative methods for a nonexpansive semigroup in Hilbert space. Comput Math Appl. 61, 2546-2554 (2011). doi:10.1016/j.camwa.2011.02.047

14. Mann, WR: Mean value methods in iteration. Proc Am Math Soc. 4, 506-510 (1953). doi:10.1090/50002-9939-19530054846-3

15. Halpern, B: Fixed points of nonexpanding maps. Bull Am Math Soc. 73, 957-961 (1967). doi:10.1090/S0002-9904-196711864-0

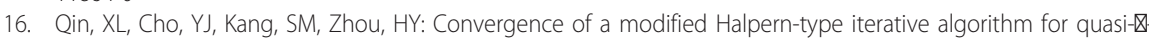
nonexpansive mappings. Appl Math Lett. 22, 1051-1055 (2009). doi:10.1016/j.aml.2009.01.015

17. Wang, ZM, Su, YF, Wang, DX, Dong, YC: A modified Halpern-type iteration algorithm for a family of hemi-relative nonexpansive mappings and systems of equilibrium problems in Banach spaces. J Comput Appl Math. 235, 2364-2371 (2011). doi:10.1016/j.cam.2010.10.036

18. Matsushita, S, Takahashi, W: A strong convergence theorem for relatively nonexpansive mappings in Banach spaces. J Approx Theory. 134, 257-266 (2005). doi:10.1016/j.jat.2005.02.007

19. Nakajo, K, Takahashi, W: Strong convergence theorems for nonexpansive mappings and nonexpansive semigroups. J Math Anal Appl. 279, 372-379 (2003). doi:10.1016/S0022-247X(02)00458-4

20. Nilsrakoo, W, Sajung, S: Strong convergence theorems by Halpern-Mann iterations for relatively non-expansive mappings in Banach spaces. Appl Math Comput 217, 6577-6586 (2011). 14, 506-510. doi:10.1016/j.amc.2011.01.040

21. Su, YF, Xu, HK, Zhang, $X$ : Strong convergence theorems for two countable families of weak relatively nonexpansive mappings and applications. Nonlinear Anal. 73, 3890-3906 (2010). doi:10.1016/j.na.2010.08.021

22. Kang, J, Su, Y, Zhang, X: Hybrid algorithm for fixed points of weak relatively nonexpansive mappings and applications. Nonlinear Anal HS. 4(4), 755-765 (2010)

23. Chang, SS, Chan, CK, Joseph Lee, HW: Modified Block iterative algorithm for quasi-ख-asymptotically nonexpansive mappings and equilibrium problem in Banach spaces. Appl Math Comput. 217, 7520-7530 (2011). doi:10.1016/j. amc.2011.02.060

24. Chang, SS, Joseph Lee, HW, Chan, CK: A new hybrid method for solving a generalized equilibrium problem solving a variational inequality problem and obtaining common fixed points in Banach spaces with applications. Nonlinear Anal TMA. 73, 2260-2270 (2010). doi:10.1016/j.na.2010.06.006

25. Blum, E, Oettli, W: From optimization and variational inequalities to equilibrium problems. Math Studient. 63(1/4), 123-145 (1994)

26. Yao, Y, Cho, YJ, Liou, Y-C: Hierarchical convergence of an implicit double-net algorithm for nonexpansive semigroups and variational inequalities. Fixed Point Theory and Applications 2011, 101 (2011). doi:10.1186/16871812-2011-101. doi:10.1186/1687-1812-2011-101

27. Yao, Y, Shahzad, N: New methods with perturbations for non-expansive mappings in Hilbert spaces. Fixed Point Theory and Applications 2011, 79 (2011). doi:10.1186/16871812-2011-79. doi:10.1186/1687-1812-2011-79

28. Yao, Y, Liou, Y-C, Wong, M-M, Yao, J-C: Strong convergence of a hybrid method for monotone variational inequalities and fixed point problems. Fixed Point Theory and Applications 2011, 53 (2011). doi:10.1186/1687-1812-2011-53. doi:10.1186/1687-1812-2011-53

29. Yao, Y, Chen, R: Regularized algorithms for hierarchical fixed-point problems. Nonlinear Anal. 74, 6826-6834 (2011). doi:10.1016/j.na.2011.07.007 
30. Yao, Y, Shahzad, N: Strong convergence of a proximal point algorithm with general errors. Optim Lett. DOI:10.1007/ s11590-011-0286-2

31. Alber, YI: Metric and generalized projection operators in Banach spaces: Properties and applications. In: Kartosator AG (ed.) Theory and Applications of Nonlinear Operators of Accretive and monotone type. pp. 15-50. Marcel Dekker, New York (1996)

doi:10.1186/1687-1812-2012-15

Cite this article as: Chang et al: Strong convergence theorems of quasi- $\phi$-asymptotically nonexpansive semigroups in Banach spaces. Fixed Point Theory and Applications 2012 2012:15.

\section{Submit your manuscript to a SpringerOpen ${ }^{\odot}$} journal and benefit from:

- Convenient online submission

- Rigorous peer review

- Immediate publication on acceptance

- Open access: articles freely available online

- High visibility within the field

- Retaining the copyright to your article

Submit your next manuscript at $\gg$ springeropen.com 